\title{
The Effect of Customer Perceived Service Quality on the Optimal Group-Buying Strategy
}

\author{
Yifan $\mathrm{Wu}^{*}$ and Ling Zhu \\ School of Business, East China University of Science and Technology, Shanghai, 200237, China \\ *Corresponding author
}

\begin{abstract}
In this paper, we study the popular group-buying model in which theseller offers discount on the group-buying websites to attract new customers coming to experience its service. This paper analyses seller's pricing decision between only running offline business and joining the group-buying business. We find that when only running offline business, higher perceived service quality will bring more profit for the seller. However, if the seller joins the group-buying website and the perceived service quality is relatively low, seller's profit will decrease with it. If the seller's service quality is higher than the perceived service quality, he will improve his regular price after joining the group-buying website. Moreover, only when the group-buying website scale is relatively big can the seller make more profit by joining the group-buying website.
\end{abstract}

Keywords-group-buying; perceived service quality; pricing; sales channel

\section{INTRODUCTION}

With the rapid development of e-commerce, online groupbuying has become a common and important sales channel for service providers. Many group-buying websites spring up all over the world since Groupon was born in 2008. In China, the group-buying trading volume in 2014 has reached 74.75 billion RMB and increased by $108.3 \%$ compared with the trading volume in 2013. However, not all sellers who join the groupbuying website could benefit from this channel. 324 sellers who ever sold products or service through group-buying website such as Groupon, LivingSocial, Open Table, Travelzoo and Buywithme are surveyed. The results show that $55.5 \%$ of the sellers joining the group-buying website benefited from this channel, $26.6 \%$ lost money and $17.9 \%$ broke even [1].

Up to now, the group-buying model has changed a lot since its emergence. Many scholars have fully studied the former models. But those models don't exist in today's group-buying website. This paper focuses on the newest and widely applied model to consider seller's revenue management which the seller just needs to announce the group-buying price and related selling period [2]. In the traditional revenue management, the decision-maker is often assumed to be myopic in the sense that he only cares about his immediate profit. However, this assumption may not hold when customers' repurchasing behavior plays an important role in the business operation. This paper differs from the previous studies on that it considers both seller's current period profit and the potential future profit.

In this paper, we consider two scenarios. In the first scenario, a seller only runs offline business and decides the regular price to maximize his profit in two periods, the current period and the future period, respectively. In the second scenario, the seller has the chance to join the group-buying website by setting the new regular offline price and online price to maximize his profit considering both the offline business and online business. Finally, the optimal profit and offline regular price are compared in these two scenarios to decide whether group-buying strategy could benefit the seller and how the seller should change his regular price.

The remainder of the paper is organized as follows. In Section 2, we present the relevant literature. Section 3 introduces the base model. Section 4 extends to the groupbuying model. We compare group-buying model with base model respectively in Section 5. Finally, we conclude our research in Section 6.

\section{LITERATURE REVIEW}

Up to now, the group buying mechanism has went through these three stages: traditional dynamic group buying mechanism, deal of the day group buying mechanism and today's group buying mechanism.

Traditional dynamic group buying mechanism announces some price-quantity schedules at the beginning of a given selling period. Customers would pay the related price given the total quantity at the end of the selling period [3]. The traditional dynamic group buying mechanism has been extensively studied in the literature. Online group-buying auction is regarded as a kind of homogeneous multi-unit auction, whose price curve steps down from one price-quantity schedule to the next [4].Online group-buying enables individual buyers to obtain the same discount as retailers who buy in large volume [5]. Data of Mobshop-listed products over various periods of time is collected and three effects are found which are important for customers' joining decision [6].Dynamic group-buying pricing mechanism outperforms fixed pricing mechanisms when the seller faces uncertain market [7]. The effect of cooperation among bidders in group-buying is analyzed and finds that cooperation can improve profits for both sellers and bidders which is different from traditional auctions [8].

In 2008, Groupon was established and it launched deal of the day group-buying with a certain product hang on the Internet every day to help small business sellers catch customers' eyes. Deal of the day group buying mechanism announces only one price-quantity pair for a given selling period. The transaction will only be done when customers' cumulative quantity reaches the given minimum deal size. 
Otherwise, there will be no transaction.Groupon broke even after running 7 months and owned 50 million dollars net income in the first year. Since then, many researchers began to study this new type of group-buying model. An in-depth descriptive analysis of the experience of Gourmet Prep Meals is conducted and finds that group-buying has a great impact on sellers' future profits [9]. The concepts of advertisement with limited availability effect and market spill-over effect are consideredto study how to set the optimal group-buying price and maximum deal size for service providers [10]. The effect of group-buying discount is investigated to study its effect on motivating informed customers to work as sales agent [11].

In 2012, Groupon began to cancel the minimum deal size. The seller just needs to set the group-buying price and selling time period. Now most group-buying websites begin to use this business model, but few academic studies have been done in this field because of its novelty. The package deal groupbuying model, which is one type of this new group-buying model is studied by formulating the basic model as a Stackelberg game where the website is the leader and the seller is the follower. They find that group-buying mechanism is more efficient when customers' seeking and communication cost factor is low. The UGS model (seller has his own groupbuying website) is more profitable than the basic model for the seller. But it only includes the online business and there is no offline business [3].Preference uncertainty and consumption state uncertainty of customersare considered and by taking a comprehensive perspective, they find that no show of voucher buyers may not be a good thing for the merchant, especially for those large or start-up ones [12]. The impact of group-buying network positive effects and other negative effects are studied on the performance of group buying business model [13]. A start-up service provider who decides whether to advertise its service product by offering temporary daily deal promotion is considered and shows that both commission rate charged by daily deal website and the discount level offered by service provider play important roles in signaling the initially unobservable quality level of the service provider [14].

To date, the most popular group buying mechanism these days is not thoroughly studied in the extant literature, which focuses on the traditional dynamic group-buying model and daily deal model with minimum deal size. This paper studies the seller's product pricing, which is considered vital for the success of group buying adoption. First, this paper researches the seller only runs the offline business and then the seller has the option to join the group-buying website. When considering seller's revenue management, we both consider the profit online and offline and the future profit, which is very meaningful for seller's decision. Finally, we find that when the website scale is relatively large, joining the group-buying website can always bring more profit for the seller. Moreover, if seller's service quality is higher than the perceived service quality, he will improve his regular price after joining the group-buying website.

\section{THE BASE MODEL}

In this study, we consider a monopolist seller running offline business by providing a service product. The seller's decision variable is the regular price. Customers have the same perceived service quality which depends on the internal standard in the service industry or customers' expectation. If the seller's actual service quality is higher than the perceived service quality, then there will be more future demand than current demand by experienced customers attracting new customers coming to experience. Otherwise, some experienced customers will be lost due to disappointment. We start from the base model using the following notations:

$p_{\mathrm{o}}$ regular price of the service

$\alpha$ customer's sensitivity to price

$\Lambda_{o}$ offline potential demand for the service

$\lambda_{o}$ offline demand for the service in the current period

$\hat{s}$ perceived service qualityof the service

$s_{o}$ actualservice quality of the seller

$\lambda_{f}$ theseller's demand in the future period

$\beta$ customer's sensitivity to quality

$v_{i}$ customers' unique valuation to seller's service product

$\eta$ cost coefficient of service quality

$\Pi_{o}$ theseller's total profit

The market is composed of a number of $\Lambda_{o}$ customers, each of whom is interested in buying a single unit of the seller's service product. Customers' valuation of the service product is composed of two terms. First, all customers gain a utility $\beta \hat{s}$, wheres can be considered as the functional perceived service qualityfrom the service product and is identical for all customers. Second, each customer also has his own unique valuation $v_{i} \sim$ Unif $[0, b]$ to the service product. Combining these two terms and subtracting the disutility because of the price, customer i's utility from buying through offline can be expressed as: $U_{i o}=\beta \hat{s}+v_{i}-\alpha p_{o}$. If $U_{i o}>0$, customer iwill purchase the service product. So there will be $\lambda_{o}=$ $\frac{b+\beta \hat{s}-\alpha p_{o}}{b} \Lambda_{o}$ customers purchase in the current period. After customer iexperiencing the service, he would realize seller's true service quality $s_{o}$. So in the future period, customer $i$ 's utility from buying through offline would be $U_{i f}=\beta s_{o}+v_{i}-$ $\alpha p_{o}$ and there will be $\lambda_{f}=\frac{b+\beta s_{o}-\alpha p_{o}}{b} \Lambda_{o}$ customers willing to buy the service product.We assume that the cost to the service quality level $s_{o}$ is given by $\eta s_{o}{ }^{2}$ [15]. Then the seller's profit maximization problem can be described as follows:

$$
\text { Maximize: } \begin{aligned}
\Pi_{o}\left(p_{o}\right)=p_{o} \lambda_{o}+p_{o} \lambda_{f}-\eta \mathrm{s}_{o}{ }^{2} \\
=p_{o}\left[\frac{2 b-2 \alpha p_{o}+\beta\left(\hat{s}+s_{o}\right)}{b}\right] \Lambda_{o}-\eta \mathrm{s}_{o}{ }^{2}
\end{aligned}
$$

Subject to: $0<\hat{s}, s_{o} \leq 1(1)$

The optimal regular price and optimal profit could be obtained by solving the first-order condition. The main results are summarized in Proposition 1.

Proposition 1: Seller's optimal regular price and profit are $p_{o}{ }^{*}=\frac{2 b+\beta\left(\hat{s}+s_{o}\right)}{4 \alpha}$ and $\Pi_{o}{ }^{*}=\frac{\left[2 b+\beta\left(\hat{s}+s_{o}\right)\right]^{2} \Lambda_{o}}{8 \alpha b}-\eta \mathrm{s}_{o}{ }^{2}$.

By analyzingthe optimal profit, we can get Theorem 1.

Theorem 1: Higher the perceived service qualitys $\hat{s}$, more profit $\Pi_{o}{ }^{*}$ will the seller gain.

From Theorem 1, we can get that sellers would struggling to improve service industry's perceived service quality because 
it can improve profit for all sellers in the same service industry by attracting more current customers coming to experiencing the service.

\section{THE GROUP-BuYING MODEL}

In this model, we consider an offline seller who has the option to cooperate with group-buying websites. We assume the seller changes the offline regular price and chooses the online price given the trading commission charged by the group-buying website.The seller runs online group buying business and offline regular business at the same time in the current period and exits the online business in the future period. Firstly, we introduce the following notations that will be used in the new model:

$p_{\mathrm{o}}{ }^{\prime}$ new regular price of the service after joining the groupbuying website

$p_{g}$ online price of the service

$\Lambda_{g}$ group buying potential demand for the service

$\lambda_{g}$ group buying demand for the service in the current period

$\lambda_{f}$ theseller's total demand in the future period

$\rho$ trading commission charged by the website

$\Pi_{g}$ theseller's profit when he chooses to join the group-buying website

$\Delta \Pi$ theprofit gap between the group-buying channel and offline channel

In the current period, offline customers' utility can be expressed as $U_{i o}{ }^{\prime}=\beta \hat{s}+v_{i}-\alpha p_{o}{ }^{\prime}$, so there will be $\lambda_{o}{ }^{\prime}=$ $\frac{b+\beta \hat{s}-\alpha p_{o}{ }^{\prime}}{b} \Lambda_{o}$ buying through offline channel. Correspondingly, online customers' utility from buying through group-buying website is $U_{i g}=\beta \hat{s}+v_{i}-\alpha p_{g}$ and there will be $\lambda_{g}=$ $\frac{b+\beta \hat{s}-\alpha p_{g}}{b} \Lambda_{g}$ customers coming to experience the service. After customers experiencing the service, they would realize the new service quality, so when seller exits the group-buying website in the future period, customers' utility through buying the service is $U_{i f}=\beta s_{o}+v_{i}-\alpha p_{o}{ }^{\prime}$, and there will be $\lambda_{f}=$ $\frac{b+\beta s_{o}-\alpha p_{o}{ }^{\prime}}{b}\left(\Lambda_{o}+\Lambda_{g}\right)$ customers willing to buy.Then the seller's profit maximization problem can be described as follows:

$$
\begin{array}{r}
\text { Maximize: } \Pi_{g}\left(p_{o}{ }^{\prime}, p_{g}\right)=p_{o}{ }^{\prime} \lambda_{o}{ }^{\prime}+\left(p_{g}-\rho\right) \lambda_{g}+p_{o}{ }^{\prime} \lambda_{f}-\eta \mathrm{s}_{g}{ }^{2} \\
=p_{o}{ }^{\prime}\left[\frac{b+\beta \hat{s}-\alpha p_{o}{ }^{\prime}}{b} \Lambda_{o}+\frac{b+\beta s_{o}-\alpha p_{o}{ }^{\prime}}{b}\left(\Lambda_{o}+\Lambda_{g}\right)\right] \\
+\left(p_{g}-\rho\right) \frac{b+\beta \hat{s}-\alpha p_{g}}{b} \Lambda_{g}-\eta \mathrm{s}_{o}{ }^{2}
\end{array}
$$

Subject to: $0<\hat{s}, s_{o} \leq 1(2)$

Aftersome algebraic calculus, we can prove that $\Pi_{g}$ is concave with both $p_{o}{ }^{\prime}$ and $p_{g}$, the maximization problem (2) is easy to solve, and we can get the following Proposition 2 which derives from seller's optimal decision on regular price and online price.

Proposition 2: Seller's optimal offline regular price and online price are $p_{o}{ }^{*}=\frac{(b+\beta \hat{s}) \Lambda_{o}+\left(b+\beta s_{o}\right)\left(\Lambda_{o}+\Lambda_{g}\right)}{2 \alpha\left(2 \Lambda_{o}+\Lambda_{g}\right)}$ and $p_{g}{ }^{*}=\frac{b+\beta \hat{s}+\alpha \rho}{2 \alpha}$. The corresponding seller's optimal profit will be $_{g}{ }^{*}=\frac{\left[(b+\beta \hat{s}) \Lambda_{o}+\left(b+\beta s_{o}\right)\left(\Lambda_{o}+\Lambda_{g}\right)\right]^{2}}{4 \alpha b\left(2 \Lambda_{o}+\Lambda_{g}\right)}+\frac{(b+\beta \hat{s}-\alpha \rho)^{2} \Lambda_{g}}{4 \alpha b}-\eta \mathrm{s}_{o}{ }^{2}$.
Proposition 2 shows that seller will increase his online and offline price as the perceived service quality increases. By analyzing the optimal profit under this model, we can get Theorem 2.

Theorem

2:When

$\hat{s} \in$ $\left(0, \frac{(\alpha \rho-b) \Lambda_{g}\left(2 \Lambda_{o}+\Lambda_{g}\right)-b \Lambda_{o}{ }^{2}-\left(b+\beta s_{o}\right) \Lambda_{o}\left(\Lambda_{o}+\Lambda_{g}\right)}{\beta\left(\Lambda_{o}+\Lambda_{g}\right)^{2}}\right]$,the seller's optimal profit $\Pi_{g}{ }^{*}$ will decrease with the perceived service quality $\hat{s}$. Otherwise, seller's optimal profit $\Pi_{g}{ }^{*}$ will increase with the perceived service qualityŝ.

From Theorem 2, we can know that seller's optimal profit will not always increase with the perceived service quality. When seller'sperceived service quality is relatively low, there will be less customers willing to experience the service in the current period. With the increasing perceived service quality, seller will increase his offline price which leads less customers willing to experiencing the service in the future period. So, seller's total profit will decrease. However, when the perceived service quality is relatively high, there will be many customers willing to experience the service in the current period. Moreover, the seller will improve his online and offline price as the perceived service quality increases. These two effects can make up for the decreased profit from less future customers So, seller's profit increases under this circumstance.This theorem can be clearly seen in Figure 1 . When $\hat{s}<0.468$, seller's profit will decrease with the perceived service quality. But when $\hat{s} \geq 0.468$, seller's profit will have the opposite trend with the perceived service quality.

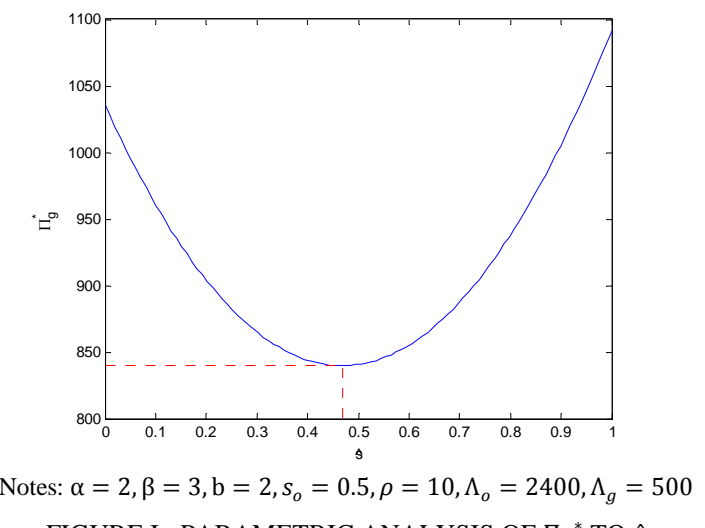

FIGURE I. PARAMETRIC ANALYSIS OF $\Pi_{g}{ }^{*}$ TO $\hat{s}$

\section{COMPARISON BETWEEN THE BASE MODEL AND GROUP-} BUYING MODEL

Comparing the profit gap between joining the group-buying website and only running offline business, we can get Proposition 3.

Proposition 3: The profit gap between these two models is $\Delta \Pi=\frac{\left[2 b+\beta\left(\hat{s}+s_{o}\right)\right]\left(2 b+3 \beta s_{o}-\beta \hat{s}\right) \Lambda_{o} \Lambda_{g}+2\left(b+\beta s_{o}\right)^{2} \Lambda_{g}{ }^{2}}{8 \alpha b\left(2 \Lambda_{o}+\Lambda_{g}\right)}+\frac{(b+\beta \hat{s}-\alpha \rho)^{2} \Lambda_{g}}{4 \alpha b}$.

Theorem 3: When the group-buying website can meet $\Lambda_{g}>\frac{\left[2 b+\beta\left(\hat{s}+s_{o}\right)\right]\left(\beta \hat{s}-2 b-3 \beta s_{o}\right) \Lambda_{o}-4(b+\beta \hat{s}-\alpha \rho)^{2} \Lambda_{o}}{2\left[\left(b+\beta s_{o}\right)^{2}+(b+\beta \hat{s}-\alpha \rho)^{2}\right]}$, joining the groupbuying website can always bring more profit for the seller. 
Theorem 3 shows that only when the group-buying website is relatively large, joining the group-buying website is a better strategy for the seller. Otherwise, it's not suitable for the seller to join.

If joining the group-buyingwebsiteis a better strategy, then we can get Theorem 4 .

Theorem 4: When $s_{o} \geq \hat{s}, p_{o}{ }^{\prime *}$ will be higher than $p_{o}{ }^{*}$; When $s_{o}<\hat{s}, p_{o}{ }^{\prime *}$ will be lower than $p_{o}{ }^{*}$.

When seller's service quality is higher than the perceived service quality, there will be more customers willing to experience the service in the future period compared with the current period. So to the seller, increasing the offline price can still bring more profit for the seller. When seller's service quality level is lower than the perceived service quality, there will be less customers willing to experience the service in the future period compared with the current period. Only decreasing the offline price can the seller attract more future customers, which can make up for the decreased offline price and help the seller make more profit. In Figure 2, we can get the seller's regular price change after joining the group-buying website. In this situation, the perceived service quality to the seller is $\hat{s}=0.5$. As we can see, when $s_{o} \geq 0.5$, the new regular price after joining the group-buying website is higher than the original price. But when $s_{o}<0.5$, the new regular price after joining the group-buying website is lower than the original price.

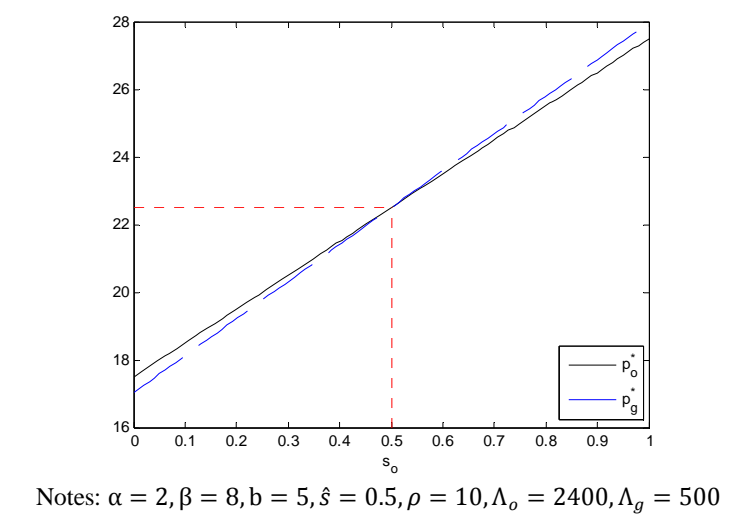

FIGURE II. PARAMETRIC ANALYSIS OF $p_{o}{ }^{\prime *}$ AND $p_{o}{ }^{*}$ TO $s_{o}$

\section{CONCLUSION}

This paper studies the seller's online group-buying pricing strategy. In the base model, we consider the seller only running offline business and find the optimal regular price for the seller. In the second model, we consider the seller has the option to join the group-buying website by changing his regular price and setting online price. Then, we compare these two models to find whether seller should join the group-buying website and how to join the group-buying website. We find that when only running offline business, higher the perceived service qualitywill bring more profit for the seller. However, if the seller joins the group-buying website and the perceived service quality is relatively low, seller's profit will decrease with it. Moreover, only when the group-buying website scale is relatively big can the seller make more profit by the joining the group-buying website. Otherwise, it would not be a good strategy. If joining the group-buying website is a better strategy, then seller will increase his regular price when the service quality is higher than the perceived service quality.

There are several other possible extensions of thisresearch. An interesting research direction is considering customers' dilution behavior in the group-buying model. It might also be interesting to consider several sellers competing to join the group-buying website.

\section{ACKNOWLEDGMENT}

This work was supported in part by the National Natural Science Foundation of China(71471062,71101051, 71431004),the Shanghai Educational Development Foundation(11CG33) and the Fundamental Research Funds for the Central Universities.

\section{REFERENCES}

[1] Dholakia, Utpal M. "How Businesses Fare with Daily Deals: A MultiSite Analysis of Groupon, Livingsocial, Opentable, Travelzoo, and BuyWithMe Promotions," Ssrn Electronic Journal, 2011.

[2] Ni, Guanqun, et al. "Optimal decisions on group buying option with a posted retail price and heterogeneous demand," Electronic Commerce Research \& Applications, vol. 14.1, pp. 23-33, 2015.

[3] Ni, Guanqun, et al. "Optimal decisions for fixed-price group-buying business originated in China: a game theoretic perspective," International Journal of Production Research, vol. 53.10, pp. 2995-3005, 2015.

[4] Kagel, John H., and Dan Levin. "Behavior in Multi - Unit Demand Auctions: Experiments with Uniform Price and Dynamic Vickrey Auctions,"Econometrica, vol. 69.2, pp. 413-454, 2001.

[5] Van Horn, Tom, Niklas Gustafsson, and Dale Woodford. "Demand aggregation through online buying groups," U.S. Patent, vol. 6, pp. 631656, Oct2003.

[6] Kauffman, Robert J., and Bin Wang. "Bid together, buy together: On the efficacy of group-buying business models in internet-based selling,"Handbook of electronic commerce in business and society, pp. 99-137, 2002.

[7] Anand, Krishnan S., and Ravi Aron. "Group buying on the web: A comparison of price-discovery mechanisms," Management Science, vol. 49.11, pp. 1546-1562, 2003.

[8] Chen, Jian, et al. "Should we collude? Analyzing the benefits of bidder cooperation in online group-buying auctions," Electronic Commerce Research and Applications, vol. 8.4, pp. 191-202, 2009.

[9] Dholakia, Utpal M., and Gur Tsabar. "A startup’s experience with running a Groupon promotion," Available at SSRN 1828003, 2011.

[10] Jiang, Xuan, and S. Deng. "Optimal strategy for selling on group-buying website," Journal of Industrial Engineering \& Management, vol. 7.4, pp. 770-784, 2014.

[11] Jing, Xiaoqing, and Jinhong Xie. "Group buying: A new mechanism for selling through social interactions," Management science, vol. 57.8, pp. 1354-1372, 2011.

[12] Gao, Fei, and Jian Chen. "The role of discount vouchers in market with customer valuation uncertainty," Production and Operations Management, vol.24.4, pp. 665-679, 2015.

[13] Zhang, Guoquan, Jennifer Shang, and Pinar Yildirim. "Optimal pricing for group buying with network effects," Omega, 2015.

[14] Zhao, Ming, Yulan Wang, and Xianghua Gan. "Signalling effect of daily deal promotion for a start-up service provider," Journal of the Operational Research Society, vol. 67.2, pp. 280-293, 2016.

[15] Tsay, Andy A., and Narendra Agrawal. "Channel dynamics under price and service competition," Manufacturing \& Service Operations Management, vol. 2.4, pp. 372-391, 2000. 